\title{
The Problems of Testing HEMP Resilience of Electronic Equipment of Automation, Control and Relay Protection
}

\author{
Vladimir Gurevich, Ph.D* \\ Central Electrical Laboratory Israel Electric Corp., Haifa, Israel
}

*Corresponding Author: Vladimir Gurevich, Ph.D., Central Electrical Laboratory Israel Electric Corp., Haifa, Israel

\begin{abstract}
New methods and means designed for protection of control, automation, telecommunications and relay protection electronic equipment, installed at electric power facilities from destructive electromagnetic impact should be subject to various tests to prove their efficiency. Electromagnetic pulse of high-altitude nuclear explosion (HEMP) may be very difficult to test. The article addresses specific problems which occur during testing of civil electronic equipment on military test-benches, i.e. HEMP simulators, and concludes that it is not practical to conduct these tests on existing simulators.
\end{abstract}

Keywords: electronic equipment; automatic, control, relay protection; high altitude electromagnetic pulse; HEMP; testing, HEMP simulators.

\section{INTRODUCTION}

Recently, it has become very important to ensure HEMP protection for civil systems that are part of a country's infrastructure, primarily, those of the power industry. In the USA for example, a special Directive signed by President D. Trump on March 26, 2019 is devoted to this issue; constantly acting Congress Commission to Assess the Threat to the United States from Electromagnetic Pulse (EMP) Attack; acting of SC77C Committee of International Electrotechnical Commission; acting WG C4.54 group within CIGRE and many other governmental, military and private companies.

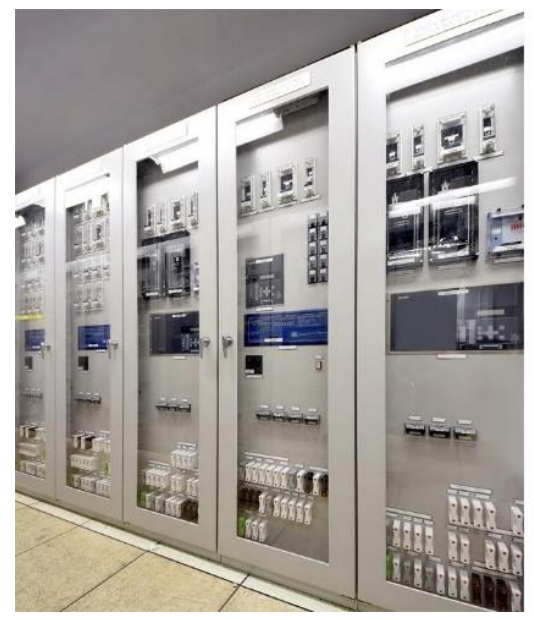

Figure1. Electronic equipment controls cabinets used in the power industry

Electronic equipment used in the power industry is represented by digital protection relays (DPR), multiple controllers, systems of automation, measurement, monitoring and data transfer, as well as the SCADA system. As a rule, these are placed in a control cabinets (Fig. 1). The design of these cabinets is suboptimal in terms of protection from HEMP electromagnetic pulse, and thus requires significant retrofit described in $[1,2]$. Such retrofit could result in rather significant complication of the cabinet's design and consequently, in cost increase. That is why it is taken for granted that the fact that efficiency of such retrofit needs to be definitely checked and confirmed experimentally.

Since E1 component of HEMP affects mostly electronic equipment, henceforth, when discussing HEMP, I mean this component exclusively. 


\section{Methods And Aims of HeMp-Resilience TeStS}

There are two major (though not exclusive) aims of control cabinets testing:

- validation of efficiency of applied protection measures and devices;

- estimation of a minimum amount of protection devices and measures to ensure adequate level of protection.

Requirements to resilience of electronic equipment to High-Altitude Electromagnetic Pulse (HEMP) have been covered in various military and civil standards. Standards such as International Electrotechnical Commission (IEC), International Telecommunication Union (ITU) and standards of US Department of Defense (MIL-STD) are widely used internationally, Fig. 2.

According to basic standards applied to industrial equipment (in particular, the standards used for power industry), i.e. IEC 61000-4-25 [3] and ITU K.78 [4], the test for electronics immunity to HEMP must be divided into two parts:

- radiated immunity test $(\mathrm{RI})$

- conducted immunity test (CI)

Normally, CI is divided into two types: pulse voltage applied to apparatus inputs/outputs and pulse currents induced into equipment circuits.

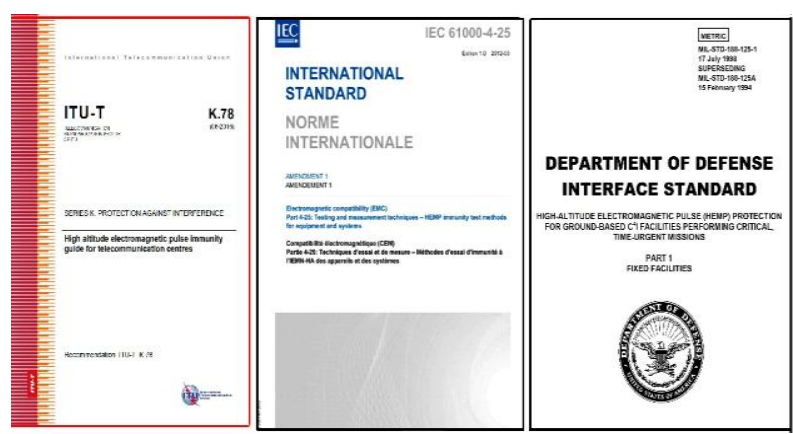

Figure2. Principal international standards stipulating protection devices and methods for HEMP-resilience testing.

Testing of CI resilience is performed by means of a special HEMP simulator.

Since electronic equipment placed in the cabinets is connected with other devices by means of multiple control and power cables, and these other devices may often be located dozens and even hundreds of meters away from the cabinets, it is absolutely obvious that RI tests should be run over the whole system rather than over a separate cabinet (Fig. 3).

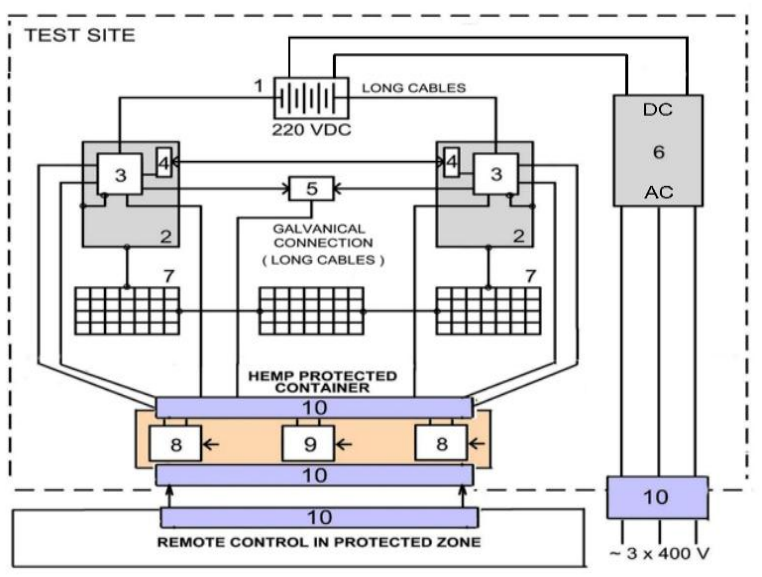

Figure3. Layout of the test-bench. 1 -Mobile battery 220V; 2 -Electrical cabinets distanced from one another; 3 - Tested electronics (such as Digital Protective Relays - DPR); 4 -Communication devices; 5 - Lockout relay 
controlled via DPR output circuits; 6 - Battery charger; 7 - Set of metal meshes comprising the ground system model; 8 - simulators of different modes of EUT operation synchronized or not with HEMP initiation system; 9 EUT status recorders; 10 - HEMP Filters

The main idea of the test process was to gradually disconnect different protection elements under continuing electromagnetic pulse impacts in order to determine the minimal (optimal) number of protection elements, which would still maintain the efficiency of electronic equipment functioning (Fig. 4).

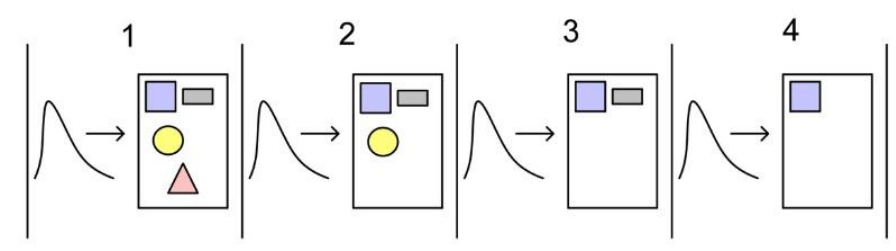

Figure4. Stages of electronic equipment testing with gradual disconnection of different protection elements and repeated generation of the test pulses.

\section{TEST BENCH - HEMP Simulator}

The most widely used type of RI HEMP simulators are so called guided wave-type simulators (Fig. 5). This simulator consists of two major parts: a source of high-voltage (several million volts) pulses and antenna system, which creates an electric field pulse (matching E1 component of HEMP) within the operational volume of the simulator, where a test object is located (Fig. 5). A pulse voltage generator (PVG), assembled according to Marx design, is used as a source of high-voltage pulses. A so-called bottom "plate" of this simulator represents a metal grid placed in a concrete foundation, while the top "plate" represents rows of stretched wire, supported by insulated supports.

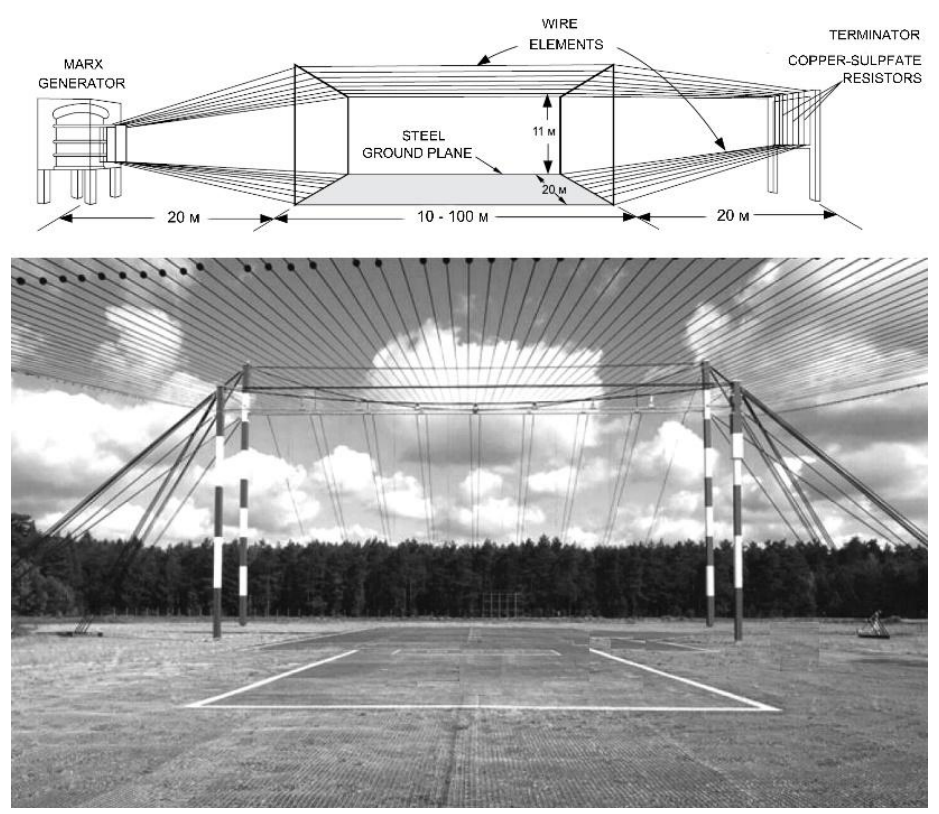

Figure5. Design and appearance of antenna system of the most widely used guided wave-type HEMP simulator.

\section{Problem 1}

Since we are talking about a very short pulse $(2.5 / 25 \mathrm{~ns})$, which affects electric circuits similar to a high-frequency signal with a frequency of up to $100 \mathrm{MHz}$, obviously variations of internal layout and external cables, as well as different types of equipment used in cabinets and different combinations of this equipment, will heavily influence high-frequency properties. For example, increase of the length of connecting wires between the protection element and the electronic equipment's input terminal under protection from $25 \mathrm{~cm}$ to $50 \mathrm{~cm}$ results in full loss of protecting capability by protection elements (e.g. varistors) [5]. Is it really possible to maintain strongly identical wiring and short connecting wires in all the cabinets with different electronic equipment inside? The answer is pretty straightforward: not at all. Therefore, does not make any sense to extrapolate the findings obtained for one cabinet to other cabinets.

International Journal of Research Studies in Electrical and Electronics Engineering (IJRSEEE) Page | 16 
The fundamental difference of military systems (armored fighting vehicles, aircrafts, missiles), which are obligatory subjected to such tests, is that all copies of the same type of equipment are manufactured based on the same drawings with strict adherence to the same technology. They feature negligibly small differences both in terms of component parts and in terms of assembly, which is performed using the same wire harness that has been previously prepared on a special templates.

\section{Problem 2}

The problem is that it is impossible to simulate HEMP impact on hundred-meter long control cables using a test-bench with 15 by 20 meters' bottom plate (or similar to that). How would you accommodate long cables in such a restricted area? If a zigzag pattern is used, the pulse induced in oppositely directed parts of the zigzag will be mutually compensated. If they are placed in concentric circles, the impact of the test-bench's electric field onto this cable will be significantly higher compared to the real situation. Combination of the two is both too complicated for calculations and almost unpredictable.

If the object being tested features short cables, sometimes the way out would be to increase the intensity of the simulator's electric field (determined theoretically) in order to obtain the outcome similar to long cables. It should be noted though that intense electric field will impact both short cables and all other items placed in the working space, e.g. control cabinets, and this is unacceptable. Placement of short cables outside the working area of the simulator (in the area of stronger fields) is also not a solution to the problem, since outside the working area the electric field is not equivalent at different points.

\section{Problem 3}

There is a problem of how to adjust the strength of the simulator's electric field during testing. The findings of computer simulation reported by Lawrence Livermore National Laboratory LLNL-TR741344 [6] suggest that the voltage amplitude on the ends of 45 and 65 meter long control cables can reach as high as $100-120 \mathrm{kV}$ at established rating of RI HEMP's electric field of $50 \mathrm{kV} / \mathrm{m}$. This means that a high voltage such as this can be applied to inputs of electronic equipment to which these cables are connected. On the other hand, does this mean that electronic equipment should really be subject to tests designed for such a significant voltage? Alternatively, let us say: do we really need to use field strength of $50 \mathrm{kV} / \mathrm{m}$ (stipulated by standards) during simulation tests, even though it causes very high voltage on control cables used for testing (and inputs of electronic equipment)? Let us consult with standards to find the answer.

The main standard IEC 61000-4-25 establishes the amplitude of the pulse voltages at the inputs of the equipment, as well as the electric field strength during the tests, depending on the actual placement and degree of protection of the equipment (test concept) to be tested.

Determination of proper test concept (out of 6 available) is the first step for defining the rules for a certain test. Standards 61000-2-11 [7] and 61000-5-3 [8] describe these concepts. Concept $2 \mathrm{~b}$ can be suitable for the EUT located inside the major reinforced concrete or all-brick building protected against lightning, but having no special protective filters. This concept allows for attenuation of EUI by $20 \mathrm{~dB}$ in the frequency band of $100 \mathrm{MHz}-30 \mathrm{MHz}$ due to the building structure. For this concept and for component E1, the strength of the radiation electrical field acting upon the tested equipment should be equal to $5 \mathrm{kV} / \mathrm{m}$ (level R4). Let us compare: for wooden buildings, providing zero EI attenuation, the strength of the electrical field equals to $50 \mathrm{kV} / \mathrm{m}$ (level R7).

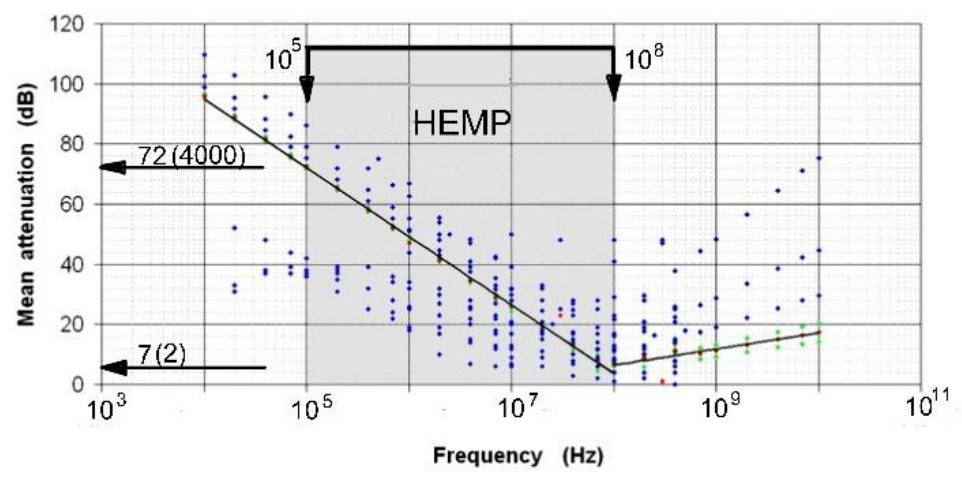

Figure6. The trend of shielding ability of reinforced concrete buildings depending on the electromagnetic emission frequency (IEC 61000-4-36)

International Journal of Research Studies in Electrical and Electronics Engineering (IJRSEEE) Page | 17 
The next step is to choose the CI test level according to IEC 61000-4-25. For the concept $2 b$, due to the presence of cables connected to the tested facility and not buried in the ground, the level of test impact should correspond to E8 (to allow for 50\% probability of the facility immunity) or E9 (to allow for 99\% probability). For E8 level, it is assumed that the tested facility is immune to the pulse voltage of $8 \mathrm{kV}$, and for E9 level - to the pulse voltage of $16 \mathrm{kV}$. A probability of $50 \%$ is deemed as normal according to the standard and can be applied to the civil equipment.

Thus, the standards suggest that the field strength adjusted on the simulator should be $5 \mathrm{kV} / \mathrm{m}$. But there are only few simulators which offer technical possibility to adjust such low rates of field strength. Secondly, thorough studying of HEMP weakening phenomenon by real buildings and structures makes me question the standards, which suggest HEMP weakening at $20 \mathrm{~dB}$ (i.e. 10-fold).

In the IEC 61000-4-36 [9] standard is shown (as the trend) the shielding ability of reinforced concrete buildings depending on the electromagnetic emission frequency, including for the frequency range corresponding to the HEMP, Fig. 6. The data obtained from numerous measurements. From Fig. 6 it can be seen that in the frequency range characterized the HEMP $\left(10^{5}-10^{8} \mathrm{~Hz}\right)$, the attenuation level by the building can change 2000 times from the beginning to the end of the frequency range! With such changes, accurate measurements of attenuation by a specific building will give little. In addition, basic instruments for measuring such attenuation [2] are designed to measure the properties of panels of a small area, such as a wall, a door, a window, and not the entire building.

Placement of electronic equipment within the room (e.g. in relation to a window or a door) can also significantly impact the rate of emission weakening. Furthermore, positioning of the district, where the building with equipment is situated relative to the Earth poles and the Equator, can also significantly influence the actual strength of HEMP's electric field affecting the equipment [2].

So, which value of electric field strength should we set up on the simulator during testing?

\section{Problem 4}

Earthing of cabinets and electronic equipment inside them is another issue to be addressed. This issue is determined on the one hand by the difference between electromagnetic pulse of lightning (LEMP) and that of a high-altitude nuclear explosion (HEMP), and on the other hand, by the design of the testbench with an earthed bottom plate.

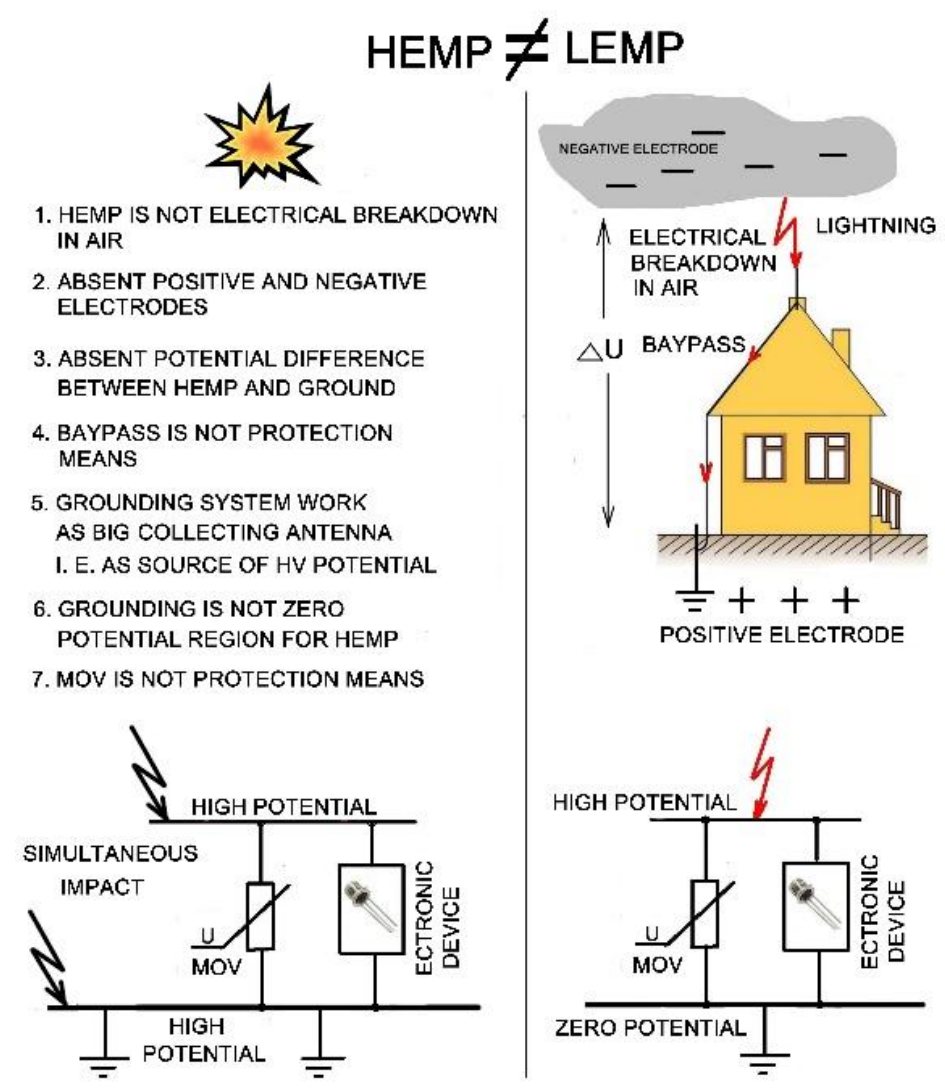

Figure7. The difference between HEMP and electromagnetic pulse of lightning (LEMP). 
LEMP is a local pinpoint electric discharge between two electrodes: a cloud and an object with earth potential (or earthing system). Whereas HEMP is not a pinpoint, but a rather extensive physical process determined by electrons quickly flowing towards earth and covering an area of thousands of kilometers. The nature of these events is absolutely different and thus the response of electrical conductors to their impact will also be different [2, 10], Fig. 7

Since the pulse of high-density electric field occurs in the guided wave-type simulator between the top insulated electrode and the bottom earthed electrode, obviously the earthed test object placed between these electrodes will respond like being struck by LEMP rather than by HEMP. In other words, such a simulator with earthed equipment placed inside simulates lightning strike, but not the impact of a highaltitude nuclear explosion. It should be noted though that earthing of the test object's metal body, e.g. the cabinet (i.e. balancing of its potential with that of the bottom plate) creates a bypass for induced current similarly to a lightning rod connected to earthing upon a lightning strike. Additionally, connection of surge protection devices between circuits of electronic equipment and the earth (i.e. the bottom plate of the simulator) will significantly weaken the impact of the test pulse (like earthing upon a lightning strike) and this can be wrongly perceived as an efficient protection against HEMP. Under real conditions, the potentials induced by HEMP in conducting elements are not connected with the earth's potential and thus earthing availability does not affect HEMP resistance of equipment. This means that use of guided wave-type simulators for electronic equipment (earthed under real conditions) testing is not practical as this distorts the real picture of HEMP impact.

The solution would be to switch to other types of simulators, so called "hybrid" simulators. This simulator also includes the Marx design pulse generator with an output voltage of several million volts, but this generator is much smaller and is powered by a chargeable accumulator battery. The generator is fixed at a certain height in the middle part of an antenna system, made up of a large biconical antenna with two long round cross-section flat cables, made up of wire mesh. These simulators can be both stationary and mobile (Fig. 8).
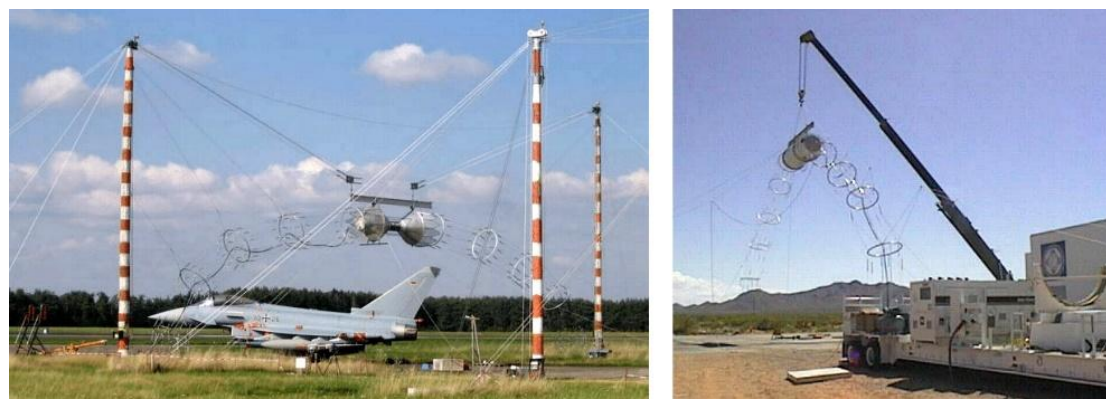

Figure8. Hybrid-type simulators: stationary (left), mobile (right).

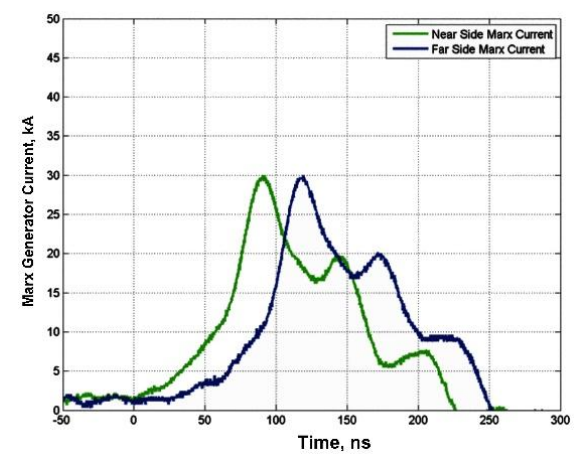

a)

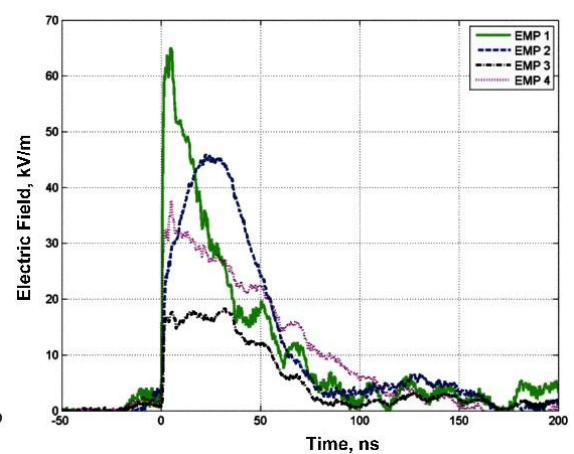

b)

Figure9. Parameters of PS-6 hybrid type simulator: a-generator's currents registered close to (left) and far away from (right) the generator; $b$-electric field created by antenna system at different settings of the generator [13].

Unfortunately, there are very few simulators of this type and they are used less frequently compared to guided wave-type simulators. In fact, guided wave-type simulators are marketed as equipment primarily used for testing aircrafts and missiles in flight, whereas hybrid-type simulators are designed for testing ground-based equipment (i.e. electronic equipment addressed in this article). 
The important advantage of such simulators is that their antenna system can be insulated from the earth [11]. However, even if it is earthed for better antenna balancing, the potential induced in the test object is not connected with that of the earth. Yet, according to [12], hybrid-type simulators create much weaker electric field (several kilovolts per meter) intended for testing shielding shells efficiency, and thus they cannot cause actuation of non-linear surge protection elements, such as varistors. According to [12], such simulators cannot be used for checking efficiency of equipment protection provided by non-linear surge protection elements. Contrary to the above, [13] suggests a description of a PS-6 hybrid-type simulator based on two interconnected portable Marx generators with output voltage of 3 million Volts each, installed at Naval Air Station Patuxent River in 2010. This simulator resembles other hybrid-type simulators (Fig. 8), but unlike previous designs it provides much higher field intensity values in its working volume (Fig. 9).

According to [13] this simulator can create an electric field of up to $77 \mathrm{kV} / \mathrm{m}$ in its working area as far as 24 meters away from the generator. The problem is that this simulator exists in a single copy so far.

\section{Problem 5}

The problem of testing electronic equipment with a high amplitude current pulse.

Common standard IEC 61000-4-25 [3] is based on IEC 61000-4-4 [14] (Russian equivalent - GOST P 51317.4.4-2007 [15]), which deals with electromagnetic compatibility and does not even mention testing with pulse current. On the other hand, IEC 61000-4-25 describes current as "short circuit currents for common mode" (160A and 320A, respectively for immunity test level EC8 and EC9). According to the p. 8.4 of the standard IEC 61000-4-25 "the tests are required for all types of conductive lines... and shielding cables". The standard does not contain definition for term "conductive lines", but it seems that it not discusses current injection into input circuits of electronic equipment. ITU K.78 [4] standard also deals with control and communication cable shield tests.

Nonetheless, when testing HEMP-resilience of equipment, a reference is often made to MIL-STD-188125-1 [16], which stipulates the necessity to test by current injection into internal circuits of electronic equipment. Is it really necessary?

According to MIL-STD-188-125-1 all tests are to be conducted relative to the ground ("common mode") and no tests have been elaborated for a so called "differential mode". In other words, between terminals of the same input or output, as well as between different inputs and outputs as stipulated in all EMC standards. Why? There is no explanation of this phenomenon in the standard.

It is noteworthy that the all tests refer to "conductive POE protective devices", whereas the values of pulse currents are given (see B.4.5 in MIL-STD-188-125-1) for shortened circuits as "short-circuit currents":

“... pulse generator requirements are defined in terms of short-circuit current and source impedance. Short-circuit current is defined as current driven through a short circuit connected to the generator output”.

Nevertheless, power supply circuits, as well as input and output circuits of electronic equipment, are not "conductive short-circuits" by any means and feature rather high impedance. So how should we test them?

Table B-I of this standard stipulates technical requirements for testing equipment, particularly for a high-voltage pulse generator. This device should generate a current pulse with an amplitude of up to 5,000 A with the source impedance of $60 \Omega$. According to the standard: "source impedance is the ratio of the generator peak open-circuit voltage to the peak short circuit current", i.e.: $R_{\text {SOURCE }}=U_{\text {OPEN }} / I_{\text {Sh.C. }}$. Thus, the requirement to "open-circuit voltage" can be determined as: $U_{\text {OPEN }}=R_{\text {SOURCE }} \times I_{\text {Sh.C. }}=60 \Omega \mathrm{x}$ $5,000 \mathrm{~A}=300,000 \mathrm{~V}$. The generator provides such parameters are really existing on the market. For example, Marx type generator, manufactured by Montena EMC company [17].

In other words, output voltage of the generator, the output terminal which is connected to a circuit with high source impedance, (such as inputs/outputs of low-voltage electronic equipment) can reach as high as hundreds of thousands of volts! Which electronic circuits could sustain this voltage? Why should this voltage be applied to these circuits as they are subject to civil standards restricting voltage at $8 \mathrm{kV}$ (level EC8) or $16 \mathrm{kV}$ (level EC9), depending on specific placement of equipment? 
These simple calculations, multiple references to conductive circuits and short-circuit currents, as well as lack of tests for "differential mode", imply that the requirements of this section are not applicable for electronic equipment. They are rather suitable for testing of conductive protection devices, such as filters, which are connected into a "common mode", and grounded cable shields.

However, some specialist dealing with these tests insists on adhering to requirements of this section of MIL-STD-188-125-1 when testing electronic equipment. It is globally true that HEMP simulators are usually maintained by military men or military industry representatives. They used to working with military standards and may often have no idea about existing sets of civil standards. When civil specialists test civil equipment on military test benches, they have no choice but to accept the rules established by the owners of the testing equipment. Hence, a supposed necessity of testing civil equipment based on MIL-STD-188-125-1 is also suggested in various scientific and technical papers. This is the reason why this research was necessary to challenge a common opinion.

A more detailed study of this problem is given in [18], on the basis of which it can be concluded that such tests are inexpedient.

\section{CONCLUSiON}

The need to protect a country's infrastructure (power industry assets in the first place) from electromagnetic pulse of high-altitude nuclear explosion (HEMP) impact makes it necessary to test HEMP-resilience of contemporary electronic equipment of automation, control and relay protection. However, this equipment, which constitutes a complex branched system and is placed in special cabinets, differs from military equipment in some aspects. These differences make it difficult or even impossible to use existing test methods and HEMP simulators designed for military equipment testing. Lack of test methods and testing equipment suitable for branched power industry's systems of automation, control and relay protection suggests that these tests are currently impractical in view of the available testing equipment. The issue of necessary tests and their procedures is not within the scope of this article.

\section{REFERENCES}

[1] Gurevich V. Protection of Substation Critical Equipment Against Intentional Electromagnetic Threats. Wiley, Chichester (UK), 2016, 228 p.

[2] Gurevich V. Protecting Electrical Equipment: Good Practices for Preventing High Altitude Electromagnetic Pulse Impacts. - De Gruyter, Berlin, 2019, 386 p.

[3] IEC 61000-4-25 Electromagnetic compatibility (EMC). - Part 4-25: Testing and measurement techniques. - HEMP immunity test methods for equipment and systems.

[4] ITU-T K.78 Series K: Protection against interference. High altitude electromagnetic pulse immunity guide for telecommunication centers. Recommendation ITU-T, 2016.

[5] Gurevich V. HEMP Protection of Electronic Equipment Located in Control Cabinets. - International Journal of Research Studies in Electrical and Electronic Engineering (IJRSEEE), 2019, Vol. 5, Iss. 1.

[6] Technical Report LLNL-TR-741344. Project FOOTPRINT: Substation Modeling and Simulations for E1 Pulses / S. D. Nelson, D. J. Larson, B. A. Kirkendall. - Lawrence Livermore National Laboratory, 2017.

[7] IEC 61000-2-11 Electromagnetic compatibility (EMC)—Part 2-11: Environment—Classification of HEMP environments.

[8] IEC/TR 61000-5-3 Electromagnetic compatibility (EMC)—Part 5-3: Installation and mitigation guidelines-HEMP protection concepts.

[9] IEC 61000-4-36 Electromagnetic compatibility (EMC) - Testing and measurement techniques - IEMI Immunity Test Methods for Equipment and Systems.

[10] Gurevich V. Testing HEMP Resilience of Electronic Equipment Used in Power Industry: Is It Essential? International Journal of Research and Innovation in Applied Science, 2019, Vol. IV, Iss. V.

[11] Baum C. E. EMP Simulators for Various Types of Nuclear EMP Environments: An Interim Categorization. - IEEE Transactions 0n Electromagnetic Compatibility, 1978, Vol. EMC-20, No. 1.

[12] Prather W. D., Giri D. V. Spectrally Flat Antenna Design and Reshaped TEM Horns. - Sensor and Simulation Notes, Note 579, 2018.

[13] Belt D., Mazuc A., Sebacher K., Bailey V., and etc. Operational Performance of the Horizontal Fast Rise EMP Pulser at the Patuxent River EMP Test Facility. - IEEE Pulsed Power Conference, Chicago, USA, 1923 June 2011. 
[14] IEC 61000-4-4 Electromagnetic compatibility (EMC) - Part 4-4: Testing and measurement techniques Electrical fast transient/burst immunity test, 2004.

[15] GOCT P 51317.4.4-2007 (in Russian).

[16] MIL-STD-188-125-1 High -Altitude Electromagnetic Pulse (HEMP) Protection for Ground Based C ${ }^{4}$ Facilities Performing Critical. Time-Urgent Mission. Part 1 Fixed Facilities, 2005.

[17] Pulsed Current Injection Test System According to MIL-STD-188-125/1 \& 2. System Description. Montena EMC, 2008.

[18] Gurevich V. Using the Requirements of the MIL-STD-188-125-1 Concerning Injection of Current Pulse at Testing Resilience of Electronic Equipment to HEMP. - International Journal of Research and Innovation in Applied Science (IJRIAS), 2019, Vol. IV, Iss. VII.

\section{AUTHOR'S BIOGRAPHY}

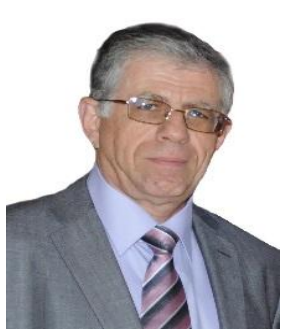

Vladimir I. Gurevich was born in Kharkov, Ukraine, in 1956. He received an M.S.E.E. degree (1978) at the Kharkov Technical University, named after P. Vasilenko, and a Ph.D. degree (1986) at Kharkov National Polytechnic University. His employment experience includes: teacher, assistant professor and associate professor at Kharkov Technical University, and chief engineer and director of Inventor, Ltd. In 1994, he arrived in Israel and works today at Israel Electric Corp. as a Senior specialist and Head of section of the Central Electric Laboratory.

He is the author of more than 200 professional papers and 15 books and holder of nearly 120 patents in the field of electrical engineering and power electronics. In 2006 he was Honorable Professor with the Kharkov Technical University.

Citation: Vladimir Gurevich, Ph.D. (2019). "The Problems of Testing HEMP Resilience of Electronic Equipment of Automation, Control and Relay Protection”. International Journal of Research Studies in Electrical and Electronics Engineering (IJRSEEE), 5(3), pp 14-22. DOI: http://dx.doi. org/10.20431/24549436.0503003

Copyright: (c) 2019 Authors. This is an open-access article distributed under the terms of the Creative Commons Attribution License, which permits unrestricted use, distribution, and reproduction in any medium, provided the original author and source are credited. 